\title{
ALGUNS PROCEDIMENTOS E EVIDÊNCIAS APLICÁVEIS
}

\author{
Ângela Mie Nakamura \\ Doutora em Controladoria e Contabilidade pela FEA/USP \\ Gerente de Estudos Fiscais do Banco Credibanco S/A
}

\section{INTRODUÇÃO}

$\mathrm{Na}$ atualidade, derivativos têm sido um tema constantemente abordado pela imprensa especializada, bem como pelos estudos e debates dos órgãos regulamentadores dos mercados financeiros e de capitais, a nível nacional e internacional.

Notícias sobre empresas estrangeiras que sofreram enormes prejuízos com o uso de derivativos têm causado dúvidas, por parte dos executivos seniores das empresas, sobre a compreensão dos efeitos a que estão expostos ao tomarem parte das operações com derivativos, acirrando o questionamento sobre sua eficácia e segurança, por parte dos órgãos reguladores do mercado financeiro.

O termo "derivativos" é utilizado para designar instrumentos financeiros que derivam ou dependem do valor de outro ativo, podendo ser os derivativos padronizados e negociados em mercados secundários organizados, ou serem um contrato ad hoc entre as partes. $O$ termo é amplo mas, usualmente, envolve contratos pertencentes ao mercado de liquidação futura, ou seja: contratos a termo (forward), contratos futuros opções de compra (call) e de venda (put) e contratos de swaps.

Os derivativos fazem parte dos "novos instrumentos financeiros", que tiveram um desenvolvimento impressionante nos últimos vinte anos.

O volume de operações feitas com derivativos no mercado internacional envolve cifras na casa de dezenas de trilhões de dólares. Os números devem ser lidos com o devido desconto pois eles são meramente nocionais. O valor nocional (notional value ou notional amount) é o valor do contrato de derivativo sobre o qual são gerados percentuais de responsabilidade efetiva.

\section{CARACTERIZAÇÃO DO PROBLEMA ANALISADO}

Os derivativos possuem natureza off-balance-sheet, uma vez que o valor nocional, na maioria das vezes, não é registrado em contas patrimoniais como Ativo ou Passivo.

Caderno de Estudos n¹3, São Paulo, FIPECAFI - Janeiro a Junho/1996 
A preocupação recai nos riscos envolvidos em tais instrumentos financeiros e na necessidade de informar com transparência à comunidade envolvida sobre os efeitos a que está exposta.

A literatura contábil disponível é recente e escassa mas é nítida a importância da Contabilidade como instrumento de controle, mensuração de valores e de evidenciação, para que os efeitos do uso de derivativos pelas empresas sejam mais bem compreendidos. Dada a importância dos derivativos no cenário econômico-financeiro, necessita-se elaborar procedimentos contábeis adequados a essas operações.

\section{OBJETIVO DO PRESENTE ARTIGO}

Avaliação crítica dos procedimentos contábeis aplicáveis a derivativos atualmente existentes no Brasil, para instituições financeiras, à luz da Teoria Contábil.

No presente artigo, trataremos dos seguintes itens:

a) estudo dos contratos pertencentes ao mercado de liquidação futura como: contratos a termo, swap, futuros e opções;

b) análise dos derivativos em relação aos aspectos contábeis aplicáveis a instituições financeiras, embora seus conceitos sejam aplicáveis às empresas em geral;

c) operações realizadas por conta própria pelas instituições financeiras, e não aquelas realizadas para seus clientes, como intermediárias;

d) relação entre risco de mercado e controle interno de derivativos.

\section{PARTICIPANTES DO MERCADO DE DERIVATIVOS}

A motivação dos participantes do mercado de derivativos pode ser resumida em:

1) HEDGE: cobertura contra risco (não é usada no caso de seguro);

2) ESPECULAÇÃO: compra e venda, de forma intensiva, de determinado ativo, seguindo as condições do mercado no instante da operação, procurando aproveitar as tendências dele para a realização de lucros; e

3) ARBRITAGEM: travar um lucro sem risco, realizando transações simultâneas em dois ou mais mercados. 


\section{TRATAMENTO CONTÁBIL NO BRASIL}

De modo geral, não há procedimento contábil específico aplicável a derivativos, à exceção das regulamentações emitidas pelo Banco Central do Brasil (BACEN) para instrumentos financeiros, no âmbito das instituições pertencentes ao Sistema Financeiro Nacional.

Resumidamente, os procedimentos contábeis aplicáveis a operações realizadas para a carteira própria das instituições financeiras são as seguintes ${ }^{1}$ :

\begin{tabular}{|c|c|}
\hline Item & Tratamento Contábil \\
\hline $\begin{array}{l}\text {-Ativos e Passivos re renda fixa com juros } \\
\text { prefixados, pós-fixados ou flutuantes }\end{array}$ & $\begin{array}{l}\text {-Custo histórico atualizado pelos juros e pela } \\
\text { correção monetária (quando cabível } \\
\text { contratado pro rata dias. } \\
\text {-Os títulos e valores mobiliários existentes no } \\
\text { Ativo com juros prefixados, pós-fixados ol } \\
\text { flutuantes estão sujeitos à constituição de } \\
\text { provisão para fazer face às desvalorizações } \\
\text { a mercado. }\end{array}$ \\
\hline -Ativos e Passivos Cambiais & $\begin{array}{l}\text { - Custo Histórico acrescido de variaçãc } \\
\text { cambial, com base na taxa de câmbio da } \\
\text { data de avaliação e juros contratados pro } \\
\text { rata dias }\end{array}$ \\
\hline $\begin{array}{l}\text {-Aplicações temporárias em ouro e mútuo } \\
\text { de ouro }\end{array}$ & -Valor de mercado. \\
\hline $\begin{array}{l}\text {-Aplicações no mercado à vista de ações } \\
\text { títulos de renda variável que não sejam } \\
\text { "derivativos" }\end{array}$ & $\begin{array}{l}\text {-Custo de aquisição atualizado pela correçãc } \\
\text { monetária, devendo-se constituir provisãd } \\
\text { para desvalorização a mercado para } \\
\text { "carteira" como um todo. }\end{array}$ \\
\hline -Derivativos & - O valor dos contratos (notonial value) \\
\hline
\end{tabular}

1 Resumo elaborado com base no Plano Contábil das Instituições do Sistema Financeiro Nacional - Cosif, do Banco Central do Brasil

Caderno de Estudos nº13, São Paulo, FIPECAFI - Janeiro a Junho/1996 


\begin{tabular}{|l|l}
\hline -Notonial Value & $\begin{array}{l}\text { registrado em conta de compensação, nãc } \\
\text { representando Ativo ou Passivo. Exceção }\end{array}$ \\
& $\begin{array}{l}\text { feita a contratos a termo, que têm seu valo } \\
\text { registrado em contas patrimoniais. }\end{array}$ \\
\hline
\end{tabular}

\begin{tabular}{|c|c|}
\hline $\begin{array}{l}\text {-Derivativos } \\
\text {-Margens dadas em garantia de operações } \\
\text { realizadas em bolsa }\end{array}$ & $\begin{array}{l}\text {-Quando em dinheiro, títulos, valores } \\
\text { mobiliários e outros ativos: Registro em } \\
\text { adequadas contas patrimoniais, devendo } \\
\text { sua remuneração ser apropriada pro rata dia } \\
\text { em contas de receita efetiva; garantias } \\
\text { dadas em fianças, apólice de seguro ol } \\
\text { semelhante: Registro em conta de } \\
\text { compensação. }\end{array}$ \\
\hline -Prêmio de opções & $\begin{array}{l}\text {-As opções pagas são registradas no Ativo } \\
\text { as opções recebidas no Passivo, pelo custo } \\
\text { histórico corrigido monetariamente } \\
\text { sujeitando-se à constituição de provisão para } \\
\text { desvalorização. }\end{array}$ \\
\hline -Contratos Futuros & $\begin{array}{l}\text {-Os ajustes diários são reconhecidos em } \\
\text { resultado quando ocorrem, portanto } \\
\text { reconhece-se o valor do mercado do } \\
\text { contrato. }\end{array}$ \\
\hline -Sinap & $\begin{array}{l}\text {-Apura-se o diferencial das taxas contratadas } \\
\text { historicamente, apropriando-se em resultado } \\
\text { Portanto, o contrato fica avaliado a taxas } \\
\text { históricas contratadas. Não há previsão para } \\
\text { contabilizar-se provisão para desvalorização } \\
\text { do mercado. }\end{array}$ \\
\hline -Contrato a termo & $\begin{array}{l}\text {-A diferença entre o preço à vista no ínicio do } \\
\text { contrato e o preço a termo é apropriamente }\end{array}$ \\
\hline
\end{tabular}

Caderno de Estudos nº13, São Paulo, FIPECAFI - Janeiro a Junho/1996 


pro rata dias em resultado. Portanto,
contrato fica avaliado a taxas históricas
contratadas. Na venda a termo descoberta,
Passivo é avaliado a mercado.

\section{PADRÃO DE CONTABILIDADE INTERNACIONAL}

Os padrões contábeis, destinados ao tratamento de derivativos, vêm sendo revisados internacionalmente, tendo em vista a importância e a preocupação crescente com relação a tais operações por parte da comunidade financeira.

O Financial Accounting Standards Board - FASB, órgão dos Estados Unidos para padronização da Contabilidade, está envolvido num projeto de longo prazo para determinação de procedimentos e princípios contábeis aplicáveis a instrumentos financeiros, tendo em vista a inexistência de procedimentos contábeis específicos aplicáveis às inovações financeiras que vêm surgindo.

\section{PROCEDIMENTOS CONTÁBEIS}

Com relação a procedimentos contábeis aplicáveis a derivativos, podemos citar os seguintes pronunciamentos dos órgãos internacionais:

-FASB no. 80, de 1984 - Accounting For Future Contracts: trata dos contratos futuros efetuados através de bolsa, com ajustes diários liquidados na clearing house (câmara de compensação).

-FASB no. 115, de 1993 - Accounting For Certain Investiment in Debt and Equity Securities: o escopo do FASB 115 abrange investimentos: (1) em títulos patrimoniais que têm fair value prontamente determinável e (2) em títulos de dívida.

-IASC - Exposure Draft e 48, de 1994 - Instrumentos Financeiros: a minuta E 48, emitida em 31 de julho de 1994, foi parcialmente transformada no pronunciamento IAS no. 32, de março de 1995, nos aspectos referentes a disclosure. Os procedimentos para reconhecimento de Ativos e Passivos financeiros serão objeto de outro pronunciamento, e o 
que a E 48 propõe são dois procedimentos contábeis possíveis: benchmark e procedimento alternativo.

O procedimento contábil por benchmark estabelece critérios baseados na intenção da operação financeira. O procedimento contábil alternativo estabelece a mensuração com base em fair value em quaisquer casos.

\section{EVIDENCIAÇÃO (DISCLOSURE)}

Os derivativos, no geral, possuem natureza off-balance-sheet, uma vez que o national amount não é Ativo ou Passivo sujeito a risco de crédito ou a risco de mercado.

Contudo, o notional amount produz resultado e, por isso, há necessidade de evidenciá-lo de forma clara, para que se informe o usuário das demonstrações financeiras, sobre o resultado que poderá ser gerado sobre as posições em aberto nos derivativos.

O projeto FASB para determinação de procedimentos e princípios contábeis, aplicáveis a instrumentos financeiros produziu, até esta data, os seguintes pronunciamentos no tocante à disclosure:

-FASB no. 105, de 1990 - Disclosure of information about financial instruments with concentrations of credit risk.

-FASB no. 107, de 1991 - Disclosure about fair value of financial instruments.

-FASB no. 119, de 1994 - Disclosure about derivate financial instruments and fair value of financial instruments.

Por outro lado, o International Accounting Standards Board - IASC transformou a parte que trata de disclosure, da minuta Exposure Draft E 48, no pronunciamento IAS no. 32 Presentation and disclosure of financial instrument, em março de 1995, e que praticamente consolida aspectos levantados separadamente nos citados FASBs no. 105, 107 e 119.

Em suma, as principais exigências de disclosure do FASB e do IASC são:

-Para cada classe de ativo ou passivo financeiro e instrumento patrimonial, reconhecido ou não:

Caderno de Estudos nº13, São Paulo, FIPECAFI - Janeiro a Junho/1996 
a) informação sobre a extensão e natureza dos instrumentos financeiros, incluindo termos e condições significativos que podem afetar o montante, timing e certeza dos fluxos de caixa futuros;

b) as políticas contábeis e métodos adotados na aplicação de padrões para reconhecimento, mensuração e apresentação;

- Riscos de taxas;

- Risco de crédito;

- Fair value dos instrumentos financeiros;

- Informações sobre hedge de transações futuras antecipadas.

- Outras evidenciações: incentivam-se as evidenciações adicionais que melhorem o entendimento do usuário das demonstrações financeiras.

A comissão de valores Mobiliários - CVM - emitiu a Instrução no. 235, em 23 de março de 1995, que "dispõe sobre a divulgação, em nota explicativa, do valor de mercado dos instrumentos financeiros, reconhecidos ou não nas demonstrações financeiras das companhias abertas, e dá outras providências".

A CVM dispõe, também, que se evidenciem os critérios e as premissas adotadas para determinação desse valor de mercado, bem como as políticas de atuação e controle das operações nos mercados derivativos e os riscos envolvidos.

O Ofício Circular / CVM / SNC / SEP no. 01, de 3 de janeiro de 1996, esclarece os dispositivos da Instrução CVM no. 235/95 e contém sugestão de notas explicativas para operações com derivativos.

O Banco Central do Brasil (BACEN) institui evidenciação mensal para as instituições financeiras, através da Circular no. 2583, de 21 de junho de 1995, dos valores líquidos e globais das posições mantidas nos mercados a termo, futuro e de opções, e em operações de swap na respectiva data-base.

\section{CONTRATOS A TERMO}

Os contratos a termo são acordos de compra ou venda de um ativo em determinada data futura, por preço previamente estabelecido.

Caderno de Estudos nº13, São Paulo, FIPECAFI - Janeiro a Junho/1996 


\section{PREÇO A TERMO}

O preço a termo "justo" deve corresponder ao valor no mercado à vista, acrescido de uma taxa de juros livre de risco para o prazo do contrato.

Basicamente, o preço a termo de ativo financeiro, sem distribuição de rendimentos periódicos, pode ser representado como:

\section{$P T=P V \times(1+i) \cdot n$}

Onde:

PT = preço a termo;

PV = preço à vista;

$\mathrm{i}$ = taxa de juros livre de risco para um período (dia, mês, ano, etc.);

$\mathrm{n}=$ número de dias, meses, anos, etc. compreendido no contrato.

\section{O VALOR DE UM CONTRATO A TERMO}

No início, o valor de um contrato a termo é zero, pois nada se desembolsa e o preço a termo "justo" deveria corresponder ao valor futuro do preço a vista, acrescido de uma taxa de juros livre de risco para o prazo do contrato. Posteriormente, poderá ter valor positivo ou negativo.

Assim, se o contrato a termo, realizado há algum tempo, for negociado durante seu prazo de vigência, poderá haver valor a desembolsar ou a receber.

O valor de um contrato a termo, portanto, pode ser considerado como sendo o valor atual da quantia pela qual o preço a termo atual excede o preço de entrega, isto é:

$V T=(P T a-P T):(1+i a)$. nd

Onde:

VT = valor do contrato a termo;

PT a = preço a termo atual;

ia = taxa de juros livre de risco atual, para um período;

Caderno de Estudos nº13, São Paulo, FIPECAFI - Janeiro a Junho/1996 
nd = número de dias, meses, anos, etc., a decorrer até o vencimento do contrato.

\section{SWAPS}

Os contratos de swaps são acordos para trocar fluxos de pagamentos futuros, representando uma fórmula preestabelecida.

O swap pode ser visualizado também como um contrato a termo. Contudo, este pressupõe a entrega do bem objeto ao final, enquanto no swap só há liquidação financeira ganho ou perda.

A forma de precificação (avaliação) do swap também é similar ao contrato a termo.

\section{CONTRATOS FUTUROS}

Os contratos futuros são compromissos de comprar e vender numa data futura, com liquidação financeira diária de ajustes do valor do contrato.

São contratos negociados em bolsas, tendo padronização da especificação do bem-objeto, seu volume, data de liquidação e entrega.

Tanto para compradores quanto para vendedores, a credibilidade da parte oposta não é levada em consideração, pois a bolsa garante a operação. Para tanto, a bolsa estabelece exigências de garantias.

Além de uma margem de garantia inicial, que pode ser aceita a critério da bolsa em dinheiro, ouro, títulos, cartas de fiança, apólices de seguro, ações, e cotas de fundos de investimento em ações, os contratos futuros têm o mecanismo de ajustes diários, isto é, as perdas e ganhos de contrato têm liquidação financeira diária.

As operações não visam propriamente a negociação de ativos, mas sim riscos de preços, daí verifica-se que raramente há liquidação de contratos pela entrega de mercadoria no vencimento. A maioria dos contratos futuros é liquidada por diferença, através da realização de operações opostas.

Caderno de Estudos nº13, São Paulo, FIPECAFI - Janeiro a Junho/1996 


\section{PREÇO DE CONTRATOS FUTUROS}

Segundo Hull ${ }^{2}$, as diferenças teóricas entre os preços a termo e a futuro são, na maioria dos casos, pequenas o suficiente para serem ignoradas.

Assim, para fins didáticos, assumidos neste estudo que as fórmulas para apurar o preço "justo" de contratos futuros são as mesmas apresentadas para contrato a termo.

\section{HEDGE COM CONTRATOS FUTUROS}

Tendo em vista a padronização dos contratos futuros, o hedge dificilmente é perfeito, com remoção de todo o risco envolvido, pelos seguintes motivos:

1- se não houver contrato futuro referenciado ao mesmo ativo que se quer "hedgiar", escolhe-se um ativo similar;

2- a data exata da compra ou venda do ativo a ser "hedgiado" pode não ser conhecida;

3- o vencimento do contrato futuro pode não coincidir com o vencimento da obrigação ou direito a ser "hedgiado".

Há modelos matemáticos desenvolvidos para apurar a quantidade ideal de contratos futuros para efetuar hedge onde não há condições para realização de hedge perfeito.

\section{OPÇÕES}

Opção é um instrumento que dá a seu titular, ou compradores, um direito sobre algo, mas não uma obrigação.

Os termos mais utilizados por aqueles que convivem diariamente nesse segmento de mercado são:

- Titular: o comprador da opção, ou seja, aquele que adquire o direito de exercê-la, pagando por isso um prêmio ou preço;

- Lançador: o vendedor da opção, ou seja, aquele que cede o direito a uma contraparte, recebendo por isso um prêmio;

- Prêmio: preço de negociação da opção, ou preço de mercado, ou ainda cotação da opção em bolsa de valores;

\footnotetext{
${ }^{2}$ HULL, John. Introdução aos mercados futuros e de opções. São Paulo, BM\&F e Cultura, 1994. p. 67.
}

Caderno de Estudos nº13, São Paulo, FIPECAFI - Janeiro a Junho/1996 
- Opção de compra: modalidade em que o titular tem o direito de comprar certo lote do ativo objeto a um preço predeterminado, até certa data. Em inglês é denominada call;

- Opção de venda: modalidade em que o titular adquire o direito de, se assim o desejar, vender ao lançador, até uma data fixada, o ativo-objeto relativo à opção e por um preço predeterminado. Em inglês é denominada pull;

- Preço de exercício: em opções de compra, é o preço que o titular deve pagar ao lançador por seu ativo-objeto, se o primeiro exercer o direito de comprar. Em opções de venda, é o preço que o lançador deve pagar ao titular se este exercer seu direito de vender seu ativo-objeto ao lançador;

- Vencimento: data em que cessam os direitos do titular de exercer sua opção;

- Séries de uma opção: opções do mesmo tipo (compra ou venda) para o mesmo ativo-objeto e com a mesma data de vencimento. Os prêmios variam conforme os preços de exercício, que diferem de uma série para outra.

As opções podem ser de estilo americano ou europeu. As opções americanas podem ser exercidas a qualquer hora, até a data de vencimento, e as opções européias, somente na data de vencimento.

As operações de opções tem, pela bolsa, cobertura de risco de inadimplência assegurada e, para tanto, há um sistema de exigência de margem de garantia de acordo com as características de operação.

O titular (comprador) não necessita depositar margem de garantia, pois o máximo que poderá perder será sempre o valor do prêmio pago.

O lançador (vendedor) da opção de compra "coberta", que deposita o bem-objeto na bolsa, também não necessita de margem, pois possui efetivamente o bem a ser vendido no exercício da opção.

Já o lançador a descoberto deve depositar a margem exigida, efetuando reforço dessa a critério da bolsa.

\section{PREÇO DAS OPÇÕES}

Black \& Scoles $^{3}$ foram os primeiros pesquisadores a fornecerem um modelo preciso para a avaliação de opções do tipo europeu, cuja fórmula apresentamos a seguir:

\footnotetext{
${ }^{3}$ BLACK, Fisher \& SCHOLES, Myron. The pricing of corporate liabilities. In: Journal of Political Econbomy. May-june, 1973. p. 637-59. 
$C=S . N(d 1)-V P(K) N(d 2)$

Onde:

$n(\underline{S})+(R f+\underline{o 2}) \cdot t$

$\mathrm{d} 1=\frac{\mathrm{K}}{\mathrm{o} \sqrt{\mathrm{t}}}$

$\ln \underline{(S)}+(R f-\underline{02}) \cdot t$

$\underline{\mathrm{d} 2=\mathrm{K}} \quad 2 \underline{0 \sqrt{\mathrm{t}}}=\mathrm{d} 1-\mathrm{o} \underline{\mathrm{t}}$

$\mathrm{C}=$ prêmio de uma opção de compra;

$\mathrm{Rf}=$ taxa continua de juros anual sem risco;

$\mathrm{t}$ = fração anual do prazo de vencimento da opção;

$\mathrm{N}(\mathrm{di})$ = área sob curva normal relativa ao coeficiente $\mathrm{i} ; \mathrm{i}=1,2$;

$\mathrm{VP}()=$. função valor presente, com taxa de desconto Rf;

$\mathrm{S}=$ preço `a vista do ativo-objeto;

$\mathrm{K}=$ preço do exercício;

$\mathrm{o}=$ volatilidade anual do ativo-objeto.

\section{HEDGE DE POSIÇÕES EM OPÇÕES}

Pode-se "hedgiar" posições em opções, comprando ou vendendo o ativo-objeto no mercado à vista, mas a forma 1:1, isto é, 1 compra (ou venda) de um contrato `a vista para 1 venda (ou compra) de um contrato de opções, não assegura o hedge otimizado. Segundo $\mathrm{Hull}^{4}$, um dos motivos de não se assegurar o hedge nessa relação 1 para 1 é que a sensibilidade de uma opção é sensível às mudanças de volatilidade. Essa segunda

${ }^{4}$ HULL, John - Introdução aos mercados futuros e de opções . São Paulo: BM\&F e Cultura, 1994. p. 295.

Caderno de Estudos nº13, São Paulo, FIPECAFI - Janeiro a Junho/1996 
dimensão do risco da opção não pode ser de forma alguma "hedgiada" através do ativoobjeto.

A quantidade de ativo-objeto a ser negociada no mercado `a vista para hedgiar cada opção européia é dada pela delta $(\Delta)$, que é uma medida de sensibilidade obtida do modelo Black \& Scholes ${ }^{5}$.

De acordo com Lemgruber:

"O delta, $\Delta$, de um ativo ou de um portfólio é definido como a taxa de variação de valor deste ativo ou de um portfólio relativo a variações no preço do ativo-objeto, S".

O delta da opção de compra européia, $\Delta c$, é:

$\Delta c=e-q t N(d 1)$

Onde:

$q$ = taxa de dividendos ou de custos de armazenagem continua e anual;

$\mathrm{t}$ = fração anual do prazo de vencimento da opção;

$\mathrm{N}(\mathrm{d} 1)$ = área sob a curva normal relativa ao $\mathrm{d} 1$.

$\frac{\mathrm{d} 1=\frac{\ln (\mathrm{S})}{\mathrm{K}}+(\mathrm{Rf}+\underline{\mathrm{o} 2}) \cdot \mathrm{t}}{\mathrm{o} \sqrt{\mathrm{t}}}$

O delta da opção da venda européia, $\Delta p$, é:

$\Delta p=e-q t N(d 1)-1$

\section{CONTROLE DE RISCO}

Os derivativos estão muito associados à idéia de risco, em especial o risco de mercado, isto é, risco de perdas em virtude de comportamento adverso dos preços em condições de mudanças ocorridas no mercado.

Organismos internacionais, a exemplo do Comitê de Basiléia ${ }^{6}$, estão empenhados em estabelecer padrões de controle de risco.

${ }^{5}$ LEMGRUSER, Eduardo Faço. Avaliação de contratos de opções. Apostila BM\&F. São Paulo, [199-----] p. 33.

Caderno de Estudos nº13, São Paulo, FIPECAFI - Janeiro a Junho/1996 
O Comitê constatou em suas pesquisas que, em muitas instituições financeiras, existem modelos internos de controle que propiciam a mensuração do risco de mercado global da empresa, expresso em termos de value-at-risk (VAR).

O VAR é o valor provável de perda que pode ser gerada pela empresa diante de oscilações desfavoráveis de preços e taxas de juros ocorridas no mercado, com um certo grau de confiança de estatística.

\section{FAIR VALUE E VALOR DE MERCADO}

Tanto o IASC quanto o FASB adotam o termo fair value para avaliação de instrumentos financeiros. Transcrevemos abaixo as definições do pronunciamento IAS no. 32.

"Fair Value é a importância pela qual um ativo poderia ser transacionado ou um passivo liquidado, entre partes conhecedoras do assunto e dispostas, numa transação sem favorecimento (arm's lenght transaction)

Valor de Mercado é a importância que se pode obter com a venda, ou a importância a pagar numa compra, de um instrumento financeiro em um mercado ativo".

O IASC e o FASB entendem que, quando um instrumento financeiro é comercializado em um mercado ativo e líquido, seus valores de mercado provêem a melhor evidência de valor justo. Esse entendimento é, à luz da teoria de mercado ${ }^{7}$.

Concluímos que o termo fair value é mais adequado do que market value para descrever um critério de avaliação contábil, pois, apesar de serem quase sinônimos num mercado eficiente, podem apresentar valores muito diferentes num mercado ineficiente, quando então, o valor de mercado não é o parâmetro próprio para avaliação.

$\mathrm{Na}$ inexistência de mercado, não há valor para ser utilizado como critério de mensuração contábil, porém há modelos matemáticos de estimação de fair value, pelo menos para instrumentos financeiros conceitualmente adequados.

\section{TEORIA CONTÁBIL E OS CRITÉRIOS CONTÁBEIS APLICÁVEIS A DERIVATIVOS}

A seguir, apresentamos o resumo das conclusões a que chegamos sobre os critérios contábeis aplicáveis a instrumentos derivativos, relacionando a teoria contábil

\footnotetext{
${ }^{6}$ O Comitê de Basiléia é um órgão de regulamentação e práticas de supervisão bancária, constituído por representantes de bancos centrais e autoridades de supervisão dos países do Grupo dos Dez (Bélgica, Canadá, França, Alemanha, Itália, Japão, Países Baixos, Suécia, Suíça, Reino Unido, Estados Unidos) e de Luxzemburgo.

${ }_{7}$ ROBERTS, Harry V. Statistical versus clinical prediction of the stck market. Unpublished to the seminar on the analysis of security prices. University of Chicago, May, 1967.
} 
correspondente efetuando uma avaliação crítica dos procedimentos contábeis atuais estabelecidos pelo BACEN e CVM.

\begin{tabular}{|c|c|c|}
\hline Contábil & $\begin{array}{l}\text { Critério Contábil aplicável } \\
\text { a derivativos conforme a } \\
\text { Teoria Contábil }\end{array}$ & $\begin{array}{l}\text { Avaliação Crítica dos } \\
\text { Procedimentos Contábeis } \\
\text { Analisados }\end{array}$ \\
\hline $\begin{array}{l}\text { Ativo: "É o futuro resultado } \\
\text { econômico que se espera } \\
\text { obter de um agente."8 } \\
\text { "(...) sob controle da } \\
\text { organização." } \\
\text { Passivo: "É o resultado } \\
\text { econômico a ser sacrificado } \\
\text { no futuro em função de } \\
\text { dívida e/ou obrigação } \\
\text { contraídas } \\
\text { terceiros"10. }\end{array}$ & $\begin{array}{l}\text { Ativo: Ganho embutido no } \\
\text { contrato de derivativo, ainda } \\
\text { não recebido. } \\
\text { Passivo: Perda embutida no } \\
\text { contrato de derivativo, ainda } \\
\text { não paga. } \\
\text { Valor Nocional: Não se } \\
\text { constitui em Ativo ou } \\
\text { Passivo, à exceção do } \\
\text { contrato a termo, que deve } \\
\text { ser registrado em contas } \\
\text { patrimoniais. }\end{array}$ & $\begin{array}{l}\text { BACEN } \\
\text {-Atende ao critério, uma vez } \\
\text { que não registra como Ativo } \\
\text { ou como Passivo o valor } \\
\text { nocional de contratos } \\
\text { futuros, swaps e opções. } \\
\text {-Os contratos a termo são } \\
\text { registrados como Ativos e } \\
\text { Passivos (tanto o valor } \\
\text { nocional de compra, quanto } \\
\text { o da venda a termo). }\end{array}$ \\
\hline $\begin{array}{l}\text { Avaliação do Ativo: "Valor } \\
\text { econômico de um ativo é o } \\
\text { valor atual máximo dos } \\
\text { resultados econômicos } \\
\text { futuros esperados, no } \\
\text { cálculo de qual a taxa de } \\
\text { desconto é a do custo de }\end{array}$ & $\begin{array}{l}\text { Avaliação do Ativo e do } \\
\text { Exigível pelo fair value: "fair } \\
\text { value é a importância pela } \\
\text { qual um ativo pode ser } \\
\text { transacionado ou um } \\
\text { passivo liquidado, entre } \\
\text { partes conhecedoras do }\end{array}$ & $\begin{array}{l}\text { BACEN (atende } \\
\text { parcialmente) } \\
\text { Avaliação por fair value } \\
\text {-Ouro; } \\
\text {-Moeda estrangeira (exceto } \\
\text { os juros) } \\
\text {-Contratos futuros; }\end{array}$ \\
\hline
\end{tabular}

\footnotetext{
${ }^{8}$ MARTINS, Eliseu. Contribuição à avaliação do ativo Intangível. São Paulo, 1972. Tese de Dourado, FEA/USP.

${ }^{9}$ HENDRIKSEN, Eidon S. \& VAN BREDA, Michael F. Accouting Theory. 5. ed., Homewood, Irwin, 1992. p. 456.

${ }^{10}$ MARTINS, Eliseu. Op cit. P. 51.
} 


\begin{tabular}{|c|c|c|}
\hline 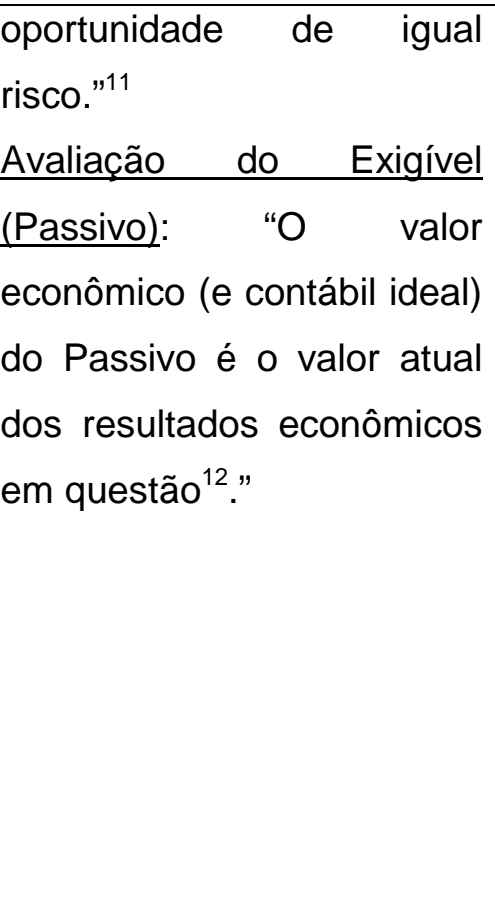 & $\begin{array}{l}\text { assunto e dispostas, numa } \\
\text { transação sem } \\
\text { favorecimento (Arm's } \\
\text { Lenght Transaction) }{ }^{13} \text {." }\end{array}$ & $\begin{array}{l}\text {-Mercado, quando inferior } \\
\text { ao custo (critério LOCOM- } \\
\text { LOWER-OF-COST-OR- } \\
\text { MARKET), para renda fixa, } \\
\text { ações, opções e demais } \\
\text { operações avaliadas com } \\
\text { base no custo histórico. } \\
\text { Não-avaliados por fair value } \\
\text {-As operações do item } \\
\text { anterior, avaliadas por } \\
\text { Locom, quando a avaliação } \\
\text { com base no custo histórico } \\
\text { for menor do que o } \\
\text { mercado. }\end{array}$ \\
\hline
\end{tabular}

\begin{tabular}{|c|c|c|}
\hline $\begin{array}{l}\text { ABELA } 13.1 \text { TEORIA CO } \\
\text { ERIVATIVOS - RESUMO }\end{array}$ & $\overline{\mathrm{DS}}$ & 5 \\
\hline Teoria Contábil & $\begin{array}{l}\text { Critério Contábil Aplicável } \\
\text { a Derivativos Conforme a } \\
\text { Teoria Contábil }\end{array}$ & $\begin{array}{l}\text { Avaliação Crítica dos } \\
\text { Procedimentos Contábeis } \\
\text { Analisados }\end{array}$ \\
\hline Realização da Receita e & Receitas e $\quad$ Despesas: & BACEN \\
\hline Confrontação das despesas & Reconhecidas a medida & parcialmente) \\
\hline (competência) & que 0 fair value dos & Atende nas situações em \\
\hline Receita: "Durante & instrumentos & que as receitas $\mathrm{e}$ as \\
\hline de tempo, & alterando. & despesas relacionadas são \\
\hline representa uma & A confrontação ocorre no & avaliadas por fair value; isto \\
\hline mensuração do & período de competência em & \\
\hline troca dos produtos (bel & que ocorre a oscilação do & -Ouro; \\
\hline
\end{tabular}

\footnotetext{
${ }^{11}$ Id. P. 41.

12 Op. Cit p. 51.

${ }^{13}$ Internacional Accounting Srtandard 32. Presentation and disclosure of financial instruments. Parágrafo 6.

${ }^{14}$ SPROUSE, Robert T. \& MOONITZ, Maurice. A tentative set of broad accounting principles for business enterprises. Accounting research. New York, AICPA, n. 3, 1962, p. 46.

${ }^{15}$ IUDícIBUS, Sérgio de. Teoria da Contabilidade $4^{\mathrm{a}}$. ed.. São Paulo, Atlas, 1994. p. 106 


\begin{tabular}{|c|c|c|}
\hline $\begin{array}{l}\text { serviços) de uma empresa } \\
\text { durante aquele período }{ }^{14} \text {." } \\
\text { "O mercado deverá validar } \\
\text { o esforço desenvolvido pela } \\
\text { empresa, atribuindo um } \\
\text { valor de troca à produção } \\
\text { de bens ou serviços }{ }^{15} . " \\
\text { “(..) A receita , desde que } \\
\text { exista um valor de mercado } \\
\text { perfeitamente definido e } \\
\text { verificável, e desde que } \\
\text { seja possível estimar as } \\
\text { despesas associadas à sua } \\
\text { produção, pode ser } \\
\text { reconhecida, não sendo } \\
\text { indispensável que os bens } \\
\text { ou serviços tenham sido } \\
\text { transferidos ao cliente }{ }^{16} \text {." } \\
\text { Despesa: "Em sentido } \\
\text { restrito, representa a } \\
\text { utilização ou o consumo de } \\
\text { bens e serviços, no } \\
\text { processo de produzir } \\
\text { receitas }{ }^{17 . " ~}\end{array}$ & fair value. & 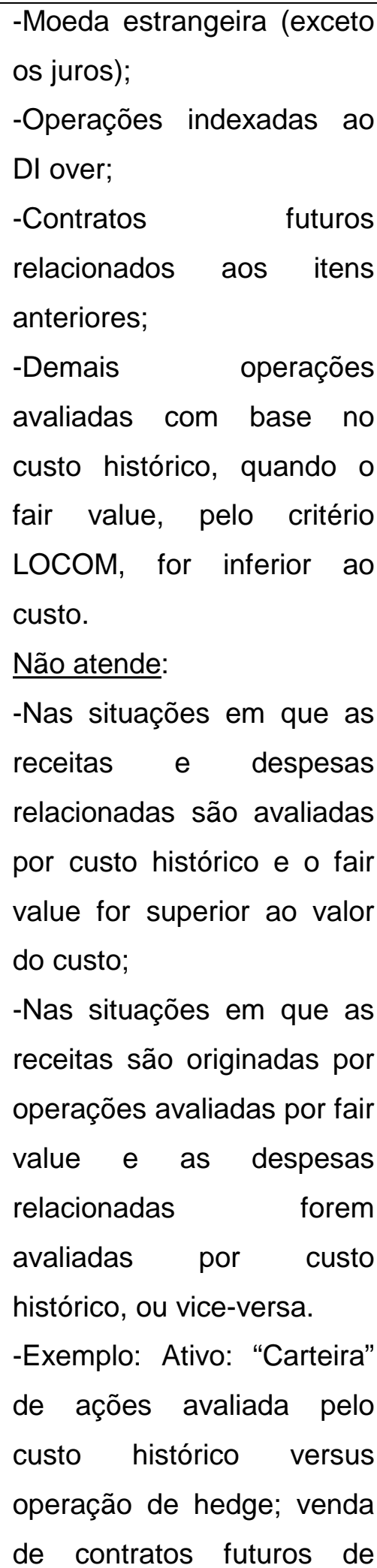 \\
\hline
\end{tabular}

\footnotetext{
${ }^{16}$ Id., ibidem. P. 106.

${ }^{17}$ Op. Cit. P. 119.
} 


\begin{tabular}{|c|c|c|}
\hline & & índices de ações. \\
\hline $\begin{array}{l}\text { Lucro ou prejuízo (redito) } \\
\text { Redito: "'E o resultado } \\
\text { econômico que pode ser } \\
\text { retirado da entidade num } \\
\text { período, de forma tal que o } \\
\text { Patrimônio Líquido no final } \\
\text { desse período seja } \\
\text { exatamente igual ao } \\
\text { inicial }{ }^{18} \text {." } \\
\text { "A mensuração do redito é a } \\
\text { diferença entre os valores } \\
\text { econômicos do Patrimônio } \\
\text { Líquido inicial e final de um } \\
\text { período, após a exclusão } \\
\text { dos acréscimos } \\
\text { decréscimos do capital e da } \\
\text { distribuição de lucros }{ }^{19} \text {." }\end{array}$ & $\begin{array}{l}\text { Reconhecimento de lucro } \\
\text { ou prejuízo all- inclusive. }\end{array}$ & $\begin{array}{l}\text { BACEN } \\
\text { parcialmente pois para } \\
\text { operações não avaliadas } \\
\text { por fair value falta o } \\
\text { resultado a ser reconhecido. }\end{array}$ \\
\hline
\end{tabular}

\begin{tabular}{|c|c|c|}
\hline Teoria Contábil & $\begin{array}{l}\text { Critério Contábil Aplicável } \\
\text { a Derivativos conforme a } \\
\text { Teoria Contábil }\end{array}$ & $\begin{array}{l}\text { Avaliação Crítica dos } \\
\text { Procedimentos Contábeis } \\
\text { Analisados }\end{array}$ \\
\hline $\begin{array}{lr}\text { Contabilidades em } & \text { Termos } \\
\text { Econômicos } & \\
\text { Modelo ideal } & \text { de } \\
\text { Contabilidade }^{20}: & \text { Ativo, } \\
\text { Passivo e } & \text { Patrimônio }\end{array}$ & $\begin{array}{l}\text { Fair value. Entendido como } \\
\text { sendo valor econômico, } \\
\text { para avaliar os derivativos. }\end{array}$ & $\begin{array}{l}\text { A Contabilidade, no geral, } \\
\text { atende parcialmente ao } \\
\text { modelo ideal de } \\
\text { Contabilidade. }\end{array}$ \\
\hline
\end{tabular}

\footnotetext{
${ }^{18}$ Martins, Eliseu. Op cit. P. 52.

${ }^{19}$ Id., Ibidem.

${ }^{20}$ MARTINS, Eliseu . op. Cit. Capítulo 4.
}

Caderno de Estudos nº13, São Paulo, FIPECAFI - Janeiro a Junho/1996 


\begin{tabular}{|c|c|c|}
\hline $\begin{array}{l}\text { Líquido Avaliados em } \\
\text { Termos Econômicos: }\end{array}$ & & \\
\hline $\begin{array}{l}\text { Evidenciação (Disclosure) } \\
\text { "Está ligado aos objetivos } \\
\text { da Contabilidade, ao } \\
\text { garantir informações } \\
\text { diferenciadas para os vários } \\
\text { tipos de usuários"." } \\
\text { "Toda informação para o } \\
\text { usuário precisa ser, ao } \\
\text { mesmo tempo, adequada, } \\
\text { justa e plena, pelo menos } \\
\text { no que se refere ao detalhe } \\
\text { que está } \\
\text { evidenciado }{ }^{22 . "}\end{array}$ & 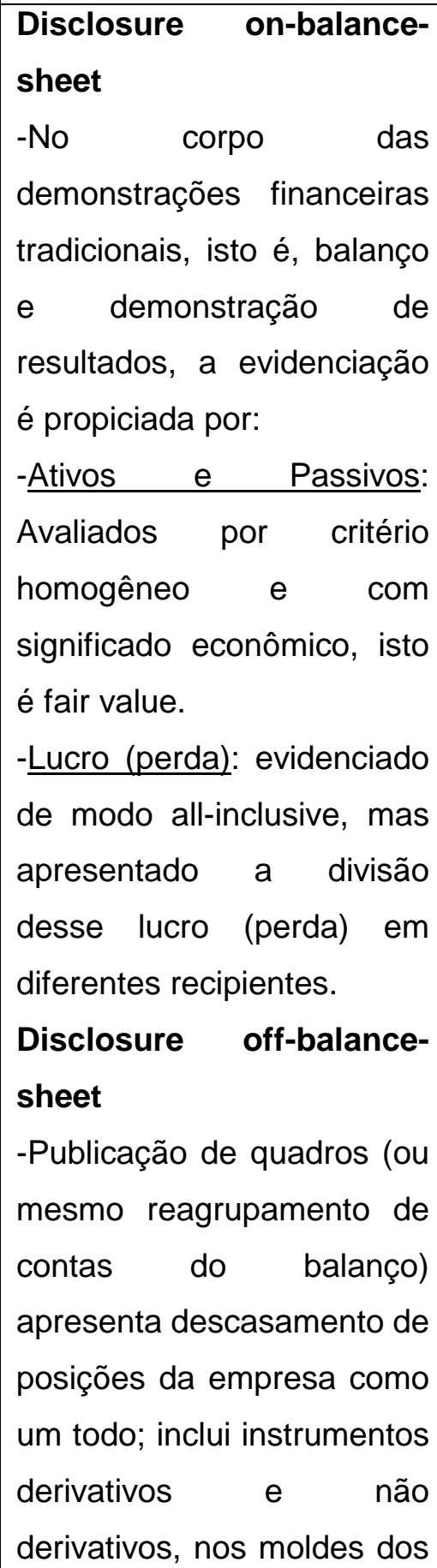 & $\begin{array}{l}\text { BACEN, } \\
\text { parcialmente. } \\
\text { Problemas: } \\
\text { Disclosure on-balance- } \\
\text { sheet: } \\
\text {-Avaliação por custo } \\
\text { histórico e em alguns casos } \\
\text { fair value. } \\
\text { Disclosure off-balance- } \\
\text { sheet: } \\
\text {-Controle contábil dos } \\
\text { derivativos: possui controle } \\
\text { em conta de compensação } \\
\text { dos contratos derivativos, à } \\
\text { exceção dos contratos a } \\
\text { termo. Porém, o registro é } \\
\text { feito por notional value. } \\
\text { Disclosure } \\
\text { O BACEN exige a } \\
\text { evidenciação das posições } \\
\text { mantidas em derivativos; } \\
\text { não exige evidenciação do } \\
\text { fair value dos instrumentos } \\
\text { financeiros em geral, nem } \\
\text { do descasamento } \\
\text { nosições para a empresa }\end{array}$ \\
\hline
\end{tabular}

\footnotetext{
${ }^{21}$ IUDÍCIBUS, Sérgio de Op. Cit. P. 81

22 op. Cit. P. 82.

${ }^{23}$ A respeito de contas de compensação: consultamos as seguintes obras: MARION, José Carlos. Uma contribuição à contabilidade de sociedade em conta de participação aplicada a empreendimentos florestais. São Paulo, 1989. Tese de Livre - Docência, FEA/USP. P. 129-130. Boletim IOB. Contas de Compensação. Caderno Temática Contábil e Balamnços. n. 49/94. CFC - Conselho Federal de Contabilidade Resolução n. 612/85. NBC - T2.5 - Das Contas de Compensação.
} 


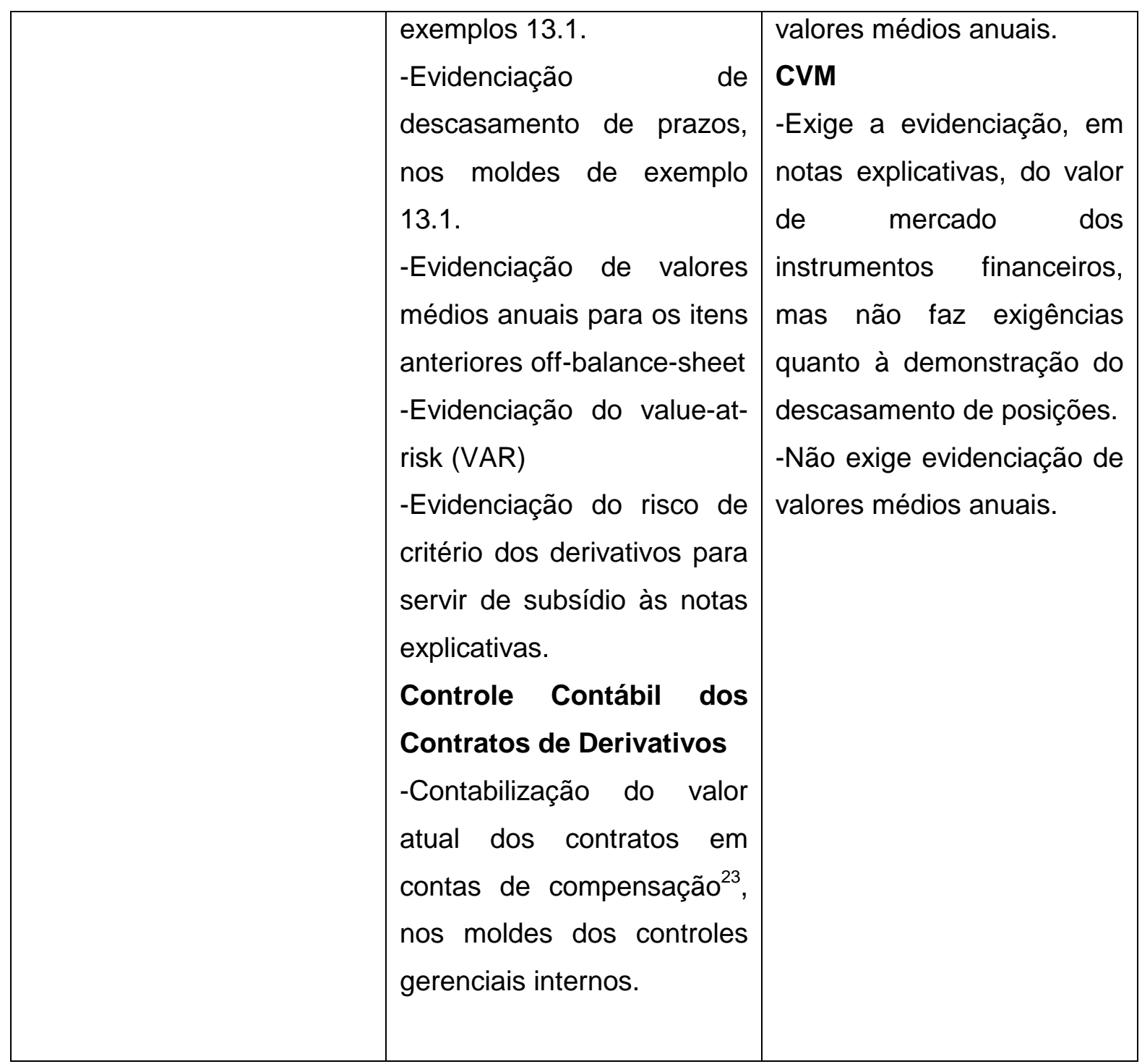

Em relação ao disclosure, elaboramos um esboço do tipo de informação que deixa clara a natureza da operação de derivativos e que dá indícios do risco de mercado a que se expõe a entidade ${ }^{24}$.

\section{Exemplo 13.1}

Vamos supor que a empresa tenha diversos contratos derivativos para "hedgiar" suas posições, conforme abaixo:

\footnotetext{
${ }^{24}$ O esboço baseou-se no "Modelo de Risco de Descasamentos" apresentado por Osias Santana de Brito, na dissertação de mestrado intitulada Contribuição ao estudo de modelos para controle de gestão em bancos de atacado. São Paulo, FEAUSP, 1993. p. 142-156. Há também idéia similar no trabalho de Cláudio Motta Camozzato, Intitulado "Balanço de Moedas e Derivativos", apresentado no congresso da ABAMEC realizado entre 9 e 12 de novembro de 1995.
} 
a) Compra de opção de compra de dólar:

-Cotação do dólar à vista $=\$ 1,00$

$-\Delta$ (delta) da call $=0,625$

-Prêmio da call $=0,02$

-Preço de exercício $=\$ 1,03$

-Para hedgiar sobre \$250 de passivo cambial (o total exposto é de \$300) e utilizando-se do conceito de delta hedge, a empresa comprou 400 calls, ao custo de $\$$ 8 e preço de exercício total valor nocional de $\$ 412$.

O valor do prêmio está dentro do ativo, no balanço a seguir apresentado, conforme procedimentos atuais.

b) Venda de contratos futuros de índice de ações:

$-\beta$ (beta) da carteira $=0,95$

-Valor do índice de ações à vista $=\$ 20$

-Valor do índice de ações futuro = $\$ 21$

-Para hedgiar a carteira de ações, com valor de mercado de $\$ 200$, em $100 \%$ foram vendidos contratos futuros de índice de ações, utilizando-se do conceito de hedge dinâmico. Assim²

$$
N^{*}=\beta \underline{S}
$$

$\mathrm{F}$

Onde:

$\mathrm{N}^{*}$ = quantidade ideal de contratos para a realização do hedge;

$\mathrm{S}=$ valor da posição a ser hedgiada;

$\mathrm{F}=$ valor do índice de ações a vista, isto é, na data do hedge;

$\beta=$ coeficiente beta, que é a medida do risco sistemático, ou de mercado, ou nãodiversificável do ativo a ser hedgiado.

$\mathrm{N}^{*}=0,95 \underline{\underline{200}}$

$N^{*}=9,50$

Valor total dos contratos vendidos (valor nocional):

${ }^{25}$ O detalhamento da equação encontra-se na obra de John Hull. Op. Cit. P. 105-109.

Caderno de Estudos nº13, São Paulo, FIPECAFI - Janeiro a Junho/1996 
$9,50 \times \$ 21=\$ 199,50$

b) Swap entre IGPM e CDI

-Valor inicial (nocional): \$100;

-Swap para pagar variação do IGPM e receber a variação da taxa do interbancário (CDI);

-Para simplificar, vamos supor que o contrato encontra-se no início, não havendo ajuste a receber ou a pagar.

Balanço conforme procedimentos atuais:

\begin{tabular}{|c|c|c|c|}
\hline \multicolumn{2}{|l|}{ Ativo Circulante } & \multicolumn{2}{|l|}{ Passivo Circulante } \\
\hline Aplic. em dep. Interf.. & $\$ 1.000$ & Depósitos interfinanceiros & $\$ 500$ \\
\hline Títulos e valores mobiliários & $\$ 208$ & Depósitos a prazo & 1.000 \\
\hline \multirow[t]{3}{*}{ Operações de crédito } & $\underline{1.792}$ & Empréstimos no exterior & 800 \\
\hline & & Total passivo circulante & 2.300 \\
\hline & & Patrimônio Líquido & 700 \\
\hline Total Ativo & $\$ 3.000$ & Total Passivo & $\$ 3.000$ \\
\hline
\end{tabular}

Notas explicativas:

\begin{tabular}{|l|c|l|}
\hline & Conta de compensação & Conta Patrimonial \\
\hline & Valor global & $\begin{array}{l}\text { Valor a receber / recebido } \\
\text { (a pagar / pago) }\end{array}$ \\
\hline $\begin{array}{l}\text { Contratos de opções } \\
\text {-Compromissos de compra } \\
\text {-Moeda estrangeira }\end{array}$ & $\$ 412,00$ & $\$ 8,00$ \\
\hline $\begin{array}{l}\text { Contratos futuros } \\
\text {-Compromissos de venda } \\
\text {-Índices de ações }\end{array}$ & $\$ 199,50$ & $\$ 0,00$ \\
\hline $\begin{array}{l}\text { Contratos de Swaps } \\
\text {-Posição ativa } \\
\text {-Mercado interfinanceiro } \\
\text {-Posição Passiva }\end{array}$ & $\$ 100,00$ & 0,00 \\
\hline
\end{tabular}

Caderno de Estudos nº13, São Paulo, FIPECAFI - Janeiro a Junho/1996 


\section{- IGP-M}

Ao invés da nota explicativa apresentada, baseada em valores nocionais, e sem mostrar a relação existente com a posição demonstrada no balanço, poderíamos elaborar quadro nos moldes seguintes:

-os saldos de contas contábeis patrimoniais, avaliados a fair value, seriam reagrupados sob títulos indicativos do tipo de risco de mercado a que estão expostos.

-os saldos patrimoniais dos derivativos seriam substituídos pelos seus equivalentes de hedge (por exemplo, o “ $\Delta$ ").

\begin{tabular}{|c|c|c|}
\hline \multicolumn{3}{|l|}{ POSIÇÃO DE RISCO: } \\
\hline Ativo & Passivo & Descasamento* \\
\hline Posição prefixada & Posição prefixada & \\
\hline Diversos & (Diversos) & $\$ 200$ \\
\hline Posição pós-fixada IGP-M & Posição pós-fixada IGP-M & \\
\hline (Diversos) & $\begin{array}{ll}\text { (Diversos) } & 200 \\
\text { Swap } & \underline{100} \\
& 300\end{array}$ & 0 \\
\hline $\begin{array}{lc}\text { Posição pós-fixada CDI } \\
\text { (Diversos) } & 1.000 \\
\text { Swap } & \underline{100} \\
& 1.100\end{array}$ & $\begin{array}{l}\text { Posição pós-fixada CDI } \\
\text { (Diversos) }\end{array}$ & 600 \\
\hline $\begin{array}{ll}\text { Posição Dólar } & \\
\text { (Diversos) } & 492 \\
\text { Call de dólar } & \underline{250} \\
& \\
& 742 \\
\end{array}$ & $\begin{array}{l}\text { Posição Dólar } \\
\text { (Diversos) }\end{array}$ & $(58)$ \\
\hline $\begin{array}{ll}\text { Posição } & \text { Mercado } \\
\text { Capitais } & \\
\text { (Diversos) } & 200\end{array}$ & $\begin{array}{lcc}\text { Posição } & \text { Mercado de } \\
\text { Capitais } & \\
\text { (Diversos) } & 800\end{array}$ & 0 \\
\hline
\end{tabular}

*Descasamento: diferença entre ativo e passivo em cada posição.

Caderno de Estudos nº13, São Paulo, FIPECAFI - Janeiro a Junho/1996 
Dada a natureza off-balance-sheet dos contratos derivativos, o mecanismo contábil que assegura controle e evidenciação é a conta de compensação.

No caso, das instituições financeiras brasileiras, o registro em conta de compensação é adequadamente, a nosso ver, obrigatório.

Os critérios de avaliação de tais contratos em conta de compensação é que são inadequados, pois limitam-se ao registro de valores nocionais.

A conta de compensação poderia fornecer informação para disclosure adequado dos contratos derivativos, utilizando-se dos conceitos de controle gerencial, isto é, registrando os valores atuais dos contratos e considerando as formas de quantificação de hedges imperfeitos $(\beta, \Delta$, etc.).

\section{CONCLUSÃO}

Do estudo efetuado, concluímos por um modelo de Contabilidade em termos econômicos adotando-se uma avaliação baseada em fair value.

Procedimentos teoricamente inadequados prejudicam o matching de receitas e despesas e, por conseguinte, da apuração do lucro.

Com relação ao controle e evidenciação dos aspectos off-balance-sheet dos derivativos, o mecanismo contábil aplicável é o sistema de contas de compensação, só que adotandose conceitos utilizados no modelo de gerenciamento interno de risco. Esse modelo controla o risco de mercado global da empresa.

Para que um modelo contábil em termos econômicos tenha efetividade prática, devemos lidar com mercados eficientes e ter acesso a fórmulas de precificação de instrumentos financeiros confiáveis e compreendidos pela comunidade envolvida.

Em vista de as técnicas de avaliação de risco ainda estarem em pleno processo de desenvolvimento, é prudente a postura adotada pelos órgãos normatizadores contábeis e internacionais, que permitem às empresas evidenciarem informações sobre derivativos com certa margem de liberdade.

\section{RESUMO}

A preocupação com relação ao tema "derivativos" recai nos riscos envolvidos em tais instrumentos financeiros e na necessidade de informar, com transparência, à comunidade envolvida, sobre os efeitos a que está exposta.

Caderno de Estudos nº13, São Paulo, FIPECAFI - Janeiro a Junho/1996 
Dada a importância dos derivativos no cenário econômico-financeiro atual e considerando-se a escassez de literatura contábil disponível, necessita-se elaborar procedimentos contábeis adequados a essas operações.

O estudo teve como objetivo efetuar uma avaliação crítica dos procedimentos contábeis aplicáveis a derivativos, atualmente existentes no Brasil para instituições financeiras á luz da Teoria Contábil.

Como resultado do estudo, elaboramos em esboço dos critérios contábeis aplicáveis a derivativos, em consonância com um modelo de contabilidade em termos econômicos, recomendado por conceituados autores, citados no presente artigo. 


\section{REFERÊNCIAS BIBLIOGRÁFICAS}

Banco Central do Brasil - Plano Contábil das Instituições do Sistema Financeiro Nacional - COSIF. Circular no. 2.583, de 21 jun. 1995.

BESSADA, Octavio - O mercado futuro e de opções . Rio de janeiro: Record, 1994.

BLACK, Fisher \& SCHOLES, Myron - The pricing of corporate liabilites. Journal of Political Economy, May-June, 1973.

BREALEY, Richard A. \& MYERS, Stewart C. - Principles of corporate finance, 4. ed., New York: Mc Graw-Hill, 1991.

BRITO, Osias Santana de - Contribuição ao estudo de modelos para controle de gestão em bancos de atacado. São Paulo, 1993. Dissertação de Mestrado, FEA-USP.

BOLETIM IOB - Contas de compensação. Caderno Temática Contábil e Balanços, no. $49 / 94$.

CAMOZZATO, Cláudio da Motta - Balanço de moedas e derivativos. Trabalho apresentado no Congresso da ABAMEC, São Paulo, 9-12 nov., 1995.

CHOI, Frederick D.S. \& MUELLER, Gerhard G. - International accounting. 2. ed., Englewood Cliffs, NJ: Prentice Hall, 1992.

COMISSÃO DE VALORES IMOBILIÁRIOS - CVM - Instrução no. 235, 23 de março de 1995.

Ofício-circular / CVM/ SNC/ SEP no. 01, 3 de Janeiro de 1996.

FINANCIAL ACCOUNTING STANDARDS BOARD - FASB:

5 - Accounting for contingrncies, mar. 1975.

- Conceptual framework for financial accounting and reporting: elements of financial statements and their measurement, 1976.

Caderno de Estudos n¹3, São Paulo, FIPECAFI - Janeiro a Junho/1996 
- Statements of financial accounting concepts no. 01. Objectives of financial reporting by business enterprises, nov. 1978.

- Statements of financial accounting concepts no. 03. Elements of financial statements of business enterprises, dez. 1980.

52 - Foreign currency translation, dec, 1981.

80 - Interest rate futures. Ago. 1984.

105 - Disclosure of information about financial instruments with off-balance-sheet risk and financial instruments with concentrations of credit risk, mar. 1990.

107 - Disclosure about fair value of financial instrument. Dez. 1991.

115 - Accounting for certain investiments in debt and equity securities. 1993.

119 - Disclosure about derivative financial instruments and fair value of financial instruments. Out. 1994.

FIPECAFI Arthur Andersen - Normas e práticas contábeis no Brasil, 2a. ed., São Paulo: Atlas, 1994.

HENDRISKEN, Eldon S. \& VAN BREDA, Michael F. - Accounting theory. 5 ed. Homewood, Irwin, 1992.

HULL, John - Introdução aos mercados futuros e de opções . São Paulo: BM\&F e Cultura, 1994.

INTERNATIONAL ACCOUNTING STANDARDS COMMITTEE - IASC:

25 - Contabilização de investimentos. Vigência a partir de 10. jan. 1987.

- Exposure draft E 48 - Instrumentos financeiros. 31 jul. 1994.

32 - Apresentação e disclosure de instrumentos financeiros. Mar. 1995.

IUDÍCIBUS, Sérgio de - Teoria da Contabilidade, 4aㅗ. Ed., São Paulo: Atlas, 1994.

KAM, Vernom. - Accounting theory. New York: John Willey \& Sons, 1986.

LEMGRUBER, Eduardo Facó - Avaliação de contrato de opções. Apostila BM \& F. São Paulo, [199_]. 
MARION, José Carlos - Uma contribuição à Contabilidade de sociedade em conta de participação aplicada a empreendimentos florestais. São Paulo, 1989. Tese de Livredocência, FEA-USP.

MARTINS, Eliseu - Contribuição `a avaliação do ativo intangível. São Paulo, 1972. Tese de Doutorado, FEA/USP.

NAKAMURA, Ângela Mie. - Contribuição ao estudo de procedimentos e evidenciação contábeis aplicáveis a operações com derivativos, voltados a instituições financeiras. São Paulo: 1996. Tese de Doutorado, FEA/USP.

PROPOSAL to issue a suplement to the Basle Accord to cover market risks. Consultative proposal by the Basle committee on banking, supervision. Basle, abr. 1995.

SANVICENTE, Antonio Zoratto \& MELLAGI FILHO, Armando - Mercado de capitais e estratégias de investimento. São Paulo: Atlas, 1988.

TEIXEIRA, Marco Aurélio - Mercados futuros, fundamentos e características operacionais. In: Curso de formação em mercados futuros. Apostila BM\&F- São Paulo, [199__ ]. 